\title{
correspondence
}

\section{Causes of cancer}

SIR,-In a recent book review I stated that "many, and perhaps most, cancers are caused by certain sexual habits, smoking habits, and gross aspects of diet rather than contaminants" (27 July, page 404). My statement runs counter to the general belief that we are currently suffering an epidemic of cancer due to a multitude of carcinogenic pollutants, and $I$ have been asked, both courteously in private correspondence and sarcastically by Ralph Chernoff (7 September, page 8 ) to substantiate it. Chiefly, those who are surprised by this statement should read the relevant reviews of cancer epidemiology (Nature 265, 589; 1978) or of cancer trends, but some relevant points can be summarised briefly.

The major age-specific trends over the past decades are not in general upwards, with the notable exception of those cancers associated with cigarette smoking. The American Cancer Society ( $A$ Journal for Clinicians, 28, (1), 20-21; 1978) have illustrated this for America, and Doll (Proc. Roy. Soc., in press) has shown it in more detail for Britain, avoiding the older age groups where the progressive elimination of mis-diagnosis produces artefactual trends. Any balanced perspective on cancer must begin with the role of smoking, not with any other aspect of the modern world. (The arguments recently advanced by the office of OSHA in the US that $20-40 \%$ of all cancer will soon be caused by industrial exposure are methodologically unsound, for the particular risks which they discuss are very considerably exaggerated.)

Smoking, particularly of cigarettes, is the chief cause of lung cancer in Britain, and smoking is strongly associated with oral and with oesophageal cancer and also, albeit less strongly, with bladder and with pancreatic cancer. Adding up appropriate proportions of the numbers who die of these cancers, smoking is responsible for about $30 \%$ of all British cancer deaths, most of this $30 \%$ being accounted for by the solidly established causal relationship betwen smoking and lung cancer.

Sexual habits are the chief known determinant of the risk of cancer of the uterine cervix, a disease which is very much commoner in prostitutes than in nuns and which is commoner among women who have had many sexual partners or who began intercourse at an early age. This disease, however accounts for only $2 \%$ of all British cancer deaths, and although we have accounted for "many" British cancer deaths by smoking, we have not yet accounted for "perhaps most" deaths, and cannot do so unless we can describe likely causes for stomach, breast or colorectal cancer. Stomach cancer used to be very common in the United States, but over the past forty years the mortality from it has decreased tenfold, so that it is now quite rare. The causes for this are quite obscure, especially since treatment has not materially improved, but since downward trends in stomach cancer are at last also developing in Britain one can hope that whatever (dietary?) aspects of the twentieth, as opposed to the nineteenth, century environment has protected the Americans will also eventually protect us.

In Britain, apart from lung $(27 \%$ of cancer deaths) and stomach (9\%), the two commonest sites are breast $(9 \%)$ and large intestine $(13 \%)$, and preventable causes for these definitely exist although they cannot as yet be identified with certainty. Early pregnancy seems to protect against breast cancer, but no practicable other way of producing these protective effects is yet known, so let us turn to diet instead. Among rats that have been pre-treated with certain carcinogens, a moderate dietary increase or decrease of certain components of "fat" will greatly increase or decrease their chances of developing breast or colon cancer. In humans, graphs of the per caput fat consumption in various countries against age-standardised cancer rates have been found to yield very striking positive correlations with fat for female colon cancer ( $81 \%$ correlation), for male colon cancer ( $85 \%$ ) and for female breast cancer $(89 \%)$. These correlations, taken together with the evidence in laboratory animals, make it plausible that some gross aspect of diet is a preventable (since people already differ with respect to it) cause of these cancers.

Of course, one particular person's fatal cancer may have had more than one preventable cause, especially if multistage models for cancer induction are approximately correct (Peto, 1977,

Origins of Human Cancer, Cold Spring

Harbor publications). However, this makes it more, rather than less, plausible that among "sexual habits, smoking habits and gross aspects of diet" (such as the consumption of certain fats or fibres) we shall find at least one preventable cause for many, and perhaps most, of today's fatal cancers. Yours faithfully,

Radcliffe Infirmary

Richard Peto

Oxford, UK

\section{World futures}

SiR,--I would like to point out some curious omissions in Lord Ashby's review of Freeman's and Jahoda's "World Futures" (9 November, page 144).

Ashby cites with approval the choice of four growth options; he forgets that there are also four decay options, which should not be left out a priori, merely on the ground that they are less cheerful than the former.

When Ashby agrees with the "outstanding practical conclusion" from the analysis, namely that the absolutely top priority is to narrow the gap between rich and poor, both within and between nations, and that this can only be done by devoting massive resources to certain problems, he fails to mention two important facts. First, that this narrowing of the gap between rich and poor is exactly what has been happening in Western industrialised countries for the last hundred years; second that the same thing is happening now between nations, without any wilful action at all. Although most poor nations have not become richer, western European countries have become immensely poorer, through the operation of political, economic and social forces, such as displacement of industry, loss of control over resources and the corresponding inflation. If this trend continues, these nations will be fully-fledged members of the Third World within a very short time, and this would of course resolve the problem of their devoting massive resources to aid other countries. Yours faithfully, S. V. V VAECK

Ministère des Affaires Economique, Brussels, Belgium.

\section{Energy forecasts}

SIR,-Your correspondent reports Amory Lovins commenting favourably on the predictive power of his tabulation of US Energy Demand Forecasts, (18 January, page 163). My analysis supports the opposite view.

Neglecting Steinhart's forecast for 2050 as outside the boundary, and taking instead the lower CONAES 2010 figure as "beyond the pale" for '78, you will discover that the range between maximum and minimum for each year of forecasts is nearly constant at $60 \mathrm{q}$. Thus as the year of forecast approaches the target year 2000 , so the percentage error on the forecasts increases! Is this knowing more and more of less and less?

Yours faithfully, J. T. D. MitChELI

Abingdon, Oxfordshire, UK.

\section{ARMS cannot negotiate}

SIR,-We were gratified to read Mr Hounsell's letter (18 January, page 171) and his expression of support for ARMS albeit with reservations. Let us allay his fears on one or two points. First, the prime objective of ARMS is to seek to develop and establish career structures for full-time research scientists in biomedical sciences, and who could be better motivated than the scientists themselves to do this. Second, we recognise that we have neither the experience nor the rights to 'negotiate' with employers (in the trade union sense) but we can at least enter into discussions, identify problems and make recommendations to both employers and the unions who aim to represent us. If researchers become diverted from working within a trade union as a result of this, then it can only mean that the unions themselves are failing to fulfil the requirements of these workers.

$$
\text { Yours faithfully, }
$$
ARLEEN UNGer

ARMS, Clinical Science Labs. Guy's Hospital, London, SE1. 